\title{
Influence of different concentrations of chia (Salvia hispanica) and flaxseed (Linum usitatissimum) meal on fillet fatty acid profile of Nile tilapia (Oreochromis niloticus)
}

\author{
Marcela Muñoz-Peñuela $^{1}(\mathbb{D})$, Manuel García-Ulloa ${ }^{1}(\mathbb{D})$, Jorge Fonseca-Madrigal $^{2}$ \\ Sergio Medina-Godoy ${ }^{1} \mathbb{D}$, Laura Gabriela Espinosa-Alonso ${ }^{1} \mathbb{D}$ \& Hervey Rodríguez-González ${ }^{1}$ \\ ${ }^{1}$ Instituto Politécnico Nacional, Centro Interdisciplinario de Investigación para el Desarrollo Integral Regional \\ Unidad Sinaloa, Guasave, Sinaloa, México \\ ${ }^{2}$ IIAF, Universidad Michoacana de San Nicolás de Hidalgo, Morelia, Michoacán, México \\ Corresponding author: Hervey Rodríguez-González (hrodriguezg@ipn.mx)
}

\begin{abstract}
The nutritional quality of tilapia fillet is characterized by low omega-3 polyunsaturated fatty acids (n-3 PUFAs). The objective of the present study was to evaluate the effect of different dietary concentrations of chia (Salvia hispanica) and flaxseed (Linum usitatissimum) meal on the omega-3 fatty acid content of tilapia (Oreochromis niloticus) fillet. Six experimental diets incorporating 5, 10, and 15\% chia or flaxseed meals, respectively, were given to the fish $(238.36 \pm 7.61 \mathrm{~g}$, initial weight $)$ for 45 days before harvesting. The $\alpha$-linolenic acid (ALA) and n-3 PUFA contents in the fillet differed significantly among diets $(P<0.05)$. Diets containing $15 \%$ chia or flaxseed meal had the highest concentrations of ALA (4.80 and 4.75\%, respectively) and n-3 PUFA (13.65 and 15.92\%, respectively). Thus, chia or flaxseed meal dietary inclusion increased the ALA and n-3 PUFA contents in the tilapia fillet. Chia or flaxseed meals are useful and potential alternatives to improve the nutritional value of $O$. niloticus fillets.
\end{abstract}

Keywords: Oreochromis niloticus; aquafeeds; plant-based feed ingredients; $\alpha$-linolenic acid; n-3 PUFA; Nile tilapia

Due to its growth rate, adaptability to culture conditions, and good market acceptance, Nile tilapia (Oreochromis niloticus) is an important food for human consumption (FAO 2016). However, the nutritional quality of tilapia fillets lags behind that of marine fish as the former contains relatively low levels of important omega-3 polyunsaturated fatty acids ( $\mathrm{n}-3$ PUFAs), such as $\alpha$-linolenic acid (ALA, 18:3n-3), eicosapentaenoic acid (EPA, 20:5n-3), and docosahexaenoic acid (DHA, 22:6n-3) (Visentainer et al. 2007). The fatty acid composition of marine fish includes low levels of n-6 PUFAs and high levels of n-3 PUFAs (predominantly EPA and DHA). However, freshwater fish like tilapia have a distinct fatty acid profile; specifically, they have high levels of n-6 PUFAs, mainly gamma-linolenic acid (GLA, 18:3n-6) and arachidonic acid (AA, 20:4n6) (Steffens 1997).
The inclusion of quality sources of long-chain PUFAs in the human diet helps prevent several cardiovascular disorders by counteracting inflammatory, thrombotic, hypertensive, and arrhythmic processes (Weaver et al. 2008). Moreover, EPA and DHA reduce the risk of rheumatoid arthritis (Kromman \& Green 1980) and are precursors for the biosynthesis of eicosanoids (Visentainer et al. 2000). Therefore, the consumption of foods containing these PUFAs is highly recommended. Formulation of balanced feeds designed to modulate the fatty acid profile of fish species that form part of the human diet represents a useful alternative to improve health (Valenzuela \& Uauy 1999).

Previous studies have assessed the impact on the fatty acid composition of Nile tilapia muscle of diets enriched with different seed oils. It has been concluded

Corresponding editor: Eduardo Ballester 
that diets enriched with flaxseed oil (FO) increased the PUFA contents of tilapia muscle (Justi et al. 2003, Visentainer et al. 2005, Tonial et al. 2009, Petenuci et al. 2018). Meanwhile, Fernandes-Montanher et al. (2016) reported that chia oil helped enhance the nutritional quality in Nile tilapia by increasing the amount of ALA in fillets. Moreover, Carbonera et al. (2014) incorporated perilla oil as a dietary lipid source resulting in a significant increase in PUFAs in tilapia muscle. Similar results were obtained when more than one kind of seed oil was included in tilapia diets (Karapanagiotidis et al. 2007, $\mathrm{Ng}$ et al. 2013). However, the base-oil diets are expensive and used at an experimental level (Carbonera et al. 2014).

The present is the first report on the use of seed meals to enhance the nutritional value of tilapia fillets in terms of n-3 PUFAs. The goal of this study was to evaluate the influence of the dietary inclusion of different concentrations of chia (Salvia hispanica) and flaxseed (Linum usitatissimum) meals on the fillet fatty acid profile of Nile tilapia.

A total of 250 Nile tilapia (male) were obtained from the broodstock of the Interdisciplinary Research Center for Regional Integral Development-Sinaloa (CIIDIR-Sinaloa) of the National Polytechnic Institute (IPN by its acronym in Spanish) in Guasave, Sinaloa, Mexico. The experimental diets were formulated according to the species requirements based on a commercial isocaloric and isoproteic feed (35\% crude protein, $\left.390 \mathrm{kcal} \mathrm{g}^{-1}\right)(\mathrm{Ng} \&$ Hanim 2007). From the control diet, six experimental diets were formulated adding 5,10 , and $15 \%$ of chia $(22.7 \%$ crude protein, $35.0 \%$ lipids, $\left.372 \mathrm{kcal} \mathrm{g}^{-1}\right)$ and flaxseed $(19.1 \%$ crude protein, $38.8 \%$ lipids, $\left.439.8 \mathrm{kcal} \mathrm{g}^{-1}\right)$ meals $(5 \mathrm{C}, 10 \mathrm{C}$, $15 \mathrm{C} ; 5 \mathrm{~F}, 10 \mathrm{~F}, 15 \mathrm{~F}$ ), respectively, as summarized in Table 1. Diets were tested with three replicates. Fish $(238.36 \pm 7.61 \mathrm{~g}$ initial weight) were kept in $3500 \mathrm{~L}$ tanks for 45 days as this is the minimum time required for the inclusion of seed oils to increase the nutritional value of adult Nile tilapia (Tonial et al. 2009). Nile tilapia were fed twice daily at $2 \%$ of total body biomass. Water temperature $\left(26.7 \pm 0.8^{\circ} \mathrm{C}\right)$, dissolved oxygen $\left(>4 \mathrm{mg} \mathrm{L}^{-1}\right)$, and ammonium $\left(<0.1 \mathrm{mg} \mathrm{L}^{-1}\right)$ were constant throughout the experiment. The final weight, specific growth rate (SGR, \% $\mathrm{d}^{-1}$ ), and feed conversion ratio (FCR) were used to assess growth and feed utilization. At the end of the experiment, all specimens were sacrificed in ice slurry immersion (Van de Vis et al. 2003) and filleted following the Ethics Commission of the College of Professors IPN-CIIDIR-Sinaloa guidelines. The fillets were placed in polyethylene bags in an $\mathrm{N}_{2}$ atmosphere and stored at $-18^{\circ} \mathrm{C}$ for subsequent analysis. The hepatosomatic (HSI $=100 \times$ [liver weight / total body weight]) and viscerosomatic (VSI $=100 \times$ [viscera weight / total body weight]) indices were calculated.

The moisture, ash, and crude protein content of the diets and tilapia fillets were determined following AOAC (1990) guidelines. The total lipids of the fillet and diet samples were extracted by homogenization in chloroform/methanol $(2: 1, \mathrm{v} / \mathrm{v})$ containing $0.01 \%$ butylated hydroxytoluene (BHT) as antioxidant following Folch et al. (1957). Fatty acid methyl esters (FAMEs) were prepared from total lipids by acidcatalyzed transesterification as described by Christie (1982) and FAME extracted and purified following Tocher \& Harvie (1988). The FAMEs were separated and quantified by gas-liquid chromatography (Fisons GC8600; Fisons Ltd., Crawley, UK) using a $30 \mathrm{~m} \times$ $0.32 \mathrm{~mm}$ capillary column (CP wax 52CB; Chrompak Ltd., London, UK). Individual methyl esters were identified by comparison with known standards and by reference to published data (Ackman 1980). Fatty acids are expressed as a percentage of the total fatty acids.

All datasets were tested for normality and homoscedasticity using the Shapiro-Wilk and Bartlett's tests, respectively. In addition, differences among the treatments were determined using the Kruskal-Wallis test, and means were compared with the Mann-Whitney U test. All statistical analyses were performed using the program Statistica 7.0.

The results of the proximate and fatty acid composition analyses of the experimental diets are summarized (Table 1). The mean lipids composition of the chia $(13.43 \%)$ and flaxseed $(13.65 \%)$ meal diets were higher than that of the control diet (10.64\%). The ALA content increased proportional to the chia (12.94, 16.83 , and $23.38 \%$ of total fatty acids) and flaxseed (10.35, 17.78 , and $21.50 \%$ of total fatty acids) meal dietary inclusion levels. The tilapia showed good acceptance of all diets throughout the experiment (45 days). The final mean weight of tilapia fed the chia $(360.13 \pm 16.98 \mathrm{~g})$ and flaxseed $(346.56 \pm 16.08 \mathrm{~g})$ meal diets were similar both to each other and to the control treatment $(317.30 \pm 36.67 \mathrm{~g} ; P>0.05)$. The SGR, and FCR of Nile tilapia adults fed the experimental diets showed no significant differences $(P$ $>0.05)$ and varied from $0.83 \pm 0.12(5 \%$ flaxseed diet $)$ to $1.35 \pm 0.15 \% \mathrm{~d}^{-1}$ (10\% flaxseed diet), and from 1.30 \pm 0.30 ( $10 \%$ flaxseed diet) to $2.13 \pm 0.58$ ( $5 \%$ flaxseed diet), respectively. No mortality occurred during the feeding trial. No significant differences $(P>0.05)$ among diets in terms of the VSI and HIS indices (4.35 to 6.78 and 1.82 to 2.54 , respectively) (Table 2).

Table 3 shows the proximate and fatty acid compositions of the tilapia fillets. Although no significant differences $(P>0.05)$ were detected among the diets regarding the fillet lipid content, all chia and flaxseed 
Table 1. Proximate and fatty acid compositions of the control and experimental diets with different chia concentrations (C) and flaxseed (F). 5C $\mathrm{C}^{\dagger}$ : 5\% chia meal dietary inclusion, 10C: 10\% chia meal dietary inclusion, 15C: 15\% chia meal dietary inclusion, 5F: 5\% flaxseed meal dietary inclusion, 10F: 10\% flaxseed meal dietary inclusion, 15F: 15\% flaxseed meal dietary inclusion.

\begin{tabular}{|c|c|c|c|c|c|c|c|}
\hline Ingredient (g) & Control & $5 \mathrm{C}^{\dagger}$ & $10 \mathrm{C}$ & $15 \mathrm{C}$ & $5 \mathrm{~F}$ & $10 \mathrm{~F}$ & $15 \mathrm{~F}$ \\
\hline Chia meal & 0.00 & 50.00 & 100.00 & 150.00 & 0.00 & 0.00 & 0.00 \\
\hline Flaxseed meal & 0.00 & 0.00 & 0.00 & 0.00 & 50.00 & 100.00 & 150.00 \\
\hline Fish meal & 196.00 & 186.20 & 176.40 & 166.60 & 186.20 & 176.40 & 166.60 \\
\hline Extruded wheat meal & 300.00 & 285.00 & 270.00 & 255.00 & 285.00 & 270.00 & 255.00 \\
\hline Wheat meal & 263.00 & 247.80 & 232.60 & 217.40 & 247.80 & 232.60 & 217.40 \\
\hline Soybean paste & 120.00 & 114.00 & 108.00 & 102.00 & 114.00 & 108.00 & 102.00 \\
\hline Fish oil & 80.00 & 76.00 & 72.00 & 68.00 & 76.00 & 72.00 & 68.00 \\
\hline Vitamin \& mineral premix & 1.00 & 1.00 & 1.00 & 1.00 & 1.00 & 1.00 & 1.00 \\
\hline Binder (grenetine) & 40.00 & 40.00 & 40.00 & 40.00 & 40.00 & 40.00 & 40.00 \\
\hline \multicolumn{8}{|c|}{ Proximate composition (\%) } \\
\hline Moisture & 7.56 & 11.38 & 9.78 & 9.00 & 11.76 & 8.69 & 8.61 \\
\hline Protein & 32.95 & 28.05 & 27.88 & 27.93 & 26.89 & 28.00 & 27.91 \\
\hline Lipid & 10.64 & 12.68 & 13.15 & 14.48 & 12.45 & 13.65 & 14.86 \\
\hline Ash & 1.27 & 0.70 & 1.07 & 1.41 & 0.53 & 0.89 & 1.18 \\
\hline Fiber & 4.97 & 4.41 & 4.26 & 4.35 & 4.26 & 4.27 & 4.29 \\
\hline Nitrogen-free extract & 50.16 & 54.16 & 53.64 & 51.83 & 56.15 & 53.19 & 51.77 \\
\hline Energy $\left(\mathrm{kcal} \mathrm{g}^{-1}\right)$ & 391.67 & 386.23 & 386.94 & 389.51 & 386.92 & 388.91 & 391.44 \\
\hline \multicolumn{8}{|l|}{ Fatty acid composition (\%) } \\
\hline $12: 0$ & 0.74 & 0.92 & 0.75 & 0.73 & 0.90 & 0.75 & 0.20 \\
\hline 14:0 & 7.80 & 6.26 & 6.15 & 5.46 & 7.25 & 7.00 & 4.67 \\
\hline 15:0 & 0.50 & 0.40 & 0.41 & 0.35 & 0.45 & 0.46 & 0.06 \\
\hline 16:0 & 25.23 & 19.88 & 19.76 & 17.94 & 21.30 & 21.27 & 17.51 \\
\hline 18:0 & 5.01 & 4.24 & 5.69 & 4.95 & 4.58 & 7.46 & 4.38 \\
\hline 20:0 & 0.00 & 0.00 & 0.00 & 0.00 & 0.00 & 0.00 & 0.00 \\
\hline Total saturated & 39.28 & 31.70 & 32.76 & 29.43 & 34.48 & 36.94 & 26.81 \\
\hline $16: 1 n-9$ & 0.00 & 0.00 & 0.00 & 0.00 & 0.00 & 0.00 & 0.00 \\
\hline $16: 1 n-7$ & 9.88 & 7.75 & 6.82 & 6.28 & 8.09 & 0.19 & 6.52 \\
\hline $18: 1 n-9$ & 15.00 & 13.06 & 12.90 & 12.16 & 16.24 & 17.23 & 17.08 \\
\hline $18: 1 n-7$ & 3.08 & 2.40 & 2.44 & 2.06 & 2.50 & 2.15 & 2.23 \\
\hline $20: 1 n-9 n-11$ & 0.90 & 0.54 & 0.92 & 0.70 & 0.65 & 0.32 & 0.80 \\
\hline Total monounsaturated & 28.85 & 23.74 & 23.08 & 21.20 & 27.48 & 19.90 & 26.62 \\
\hline $18: 2 n-6$ & 6.41 & 11.87 & 11.58 & 12.25 & 10.73 & 10.97 & 10.19 \\
\hline $20: 2 n-6$ & 0.00 & 0.00 & 0.00 & 0.00 & 0.00 & 0.00 & 0.00 \\
\hline $20: 3 n-6$ (GLA) & 0.00 & 0.00 & 0.00 & 0.00 & 0.00 & 0.00 & 0.00 \\
\hline 20:4n-6 (ARA) & 0.94 & 0.77 & 1.01 & 0.61 & 0.75 & 0.68 & 0.64 \\
\hline $22: 5 n-6$ & 0.00 & 0.00 & 0.00 & 0.00 & 0.00 & 0.00 & 0.00 \\
\hline Total n-6 PUFAs & 7.35 & 12.64 & 12.59 & 12.86 & 11.48 & 11.65 & 10.83 \\
\hline $18: 3 n-3$ (ALA) & 3.05 & 12.94 & 16.83 & 23.38 & 10.35 & 17.78 & 21.50 \\
\hline $18: 4 n-3$ & 1.25 & 1.22 & 0.89 & 0.80 & 0.99 & 0.87 & 0.91 \\
\hline $20: 4 n-3$ & 0.49 & 0.44 & 0.59 & 0.34 & 0.44 & 0.35 & 0.38 \\
\hline 20:5n-3 (EPA) & 10.73 & 9.84 & 7.38 & 6.45 & 8.17 & 6.90 & 7.08 \\
\hline $22: 4 n-3$ & 0.00 & 0.00 & 0.00 & 0.00 & 0.00 & 0.00 & 0.00 \\
\hline $22: 5 n-3$ & 2.27 & 1.75 & 1.43 & 1.45 & 1.68 & 1.43 & 1.48 \\
\hline 22:6n-3 (DHA) & 6.73 & 5.73 & 4.45 & 4.08 & 4.93 & 4.18 & 4.41 \\
\hline Total n-3 PUFAs & 24.52 & 31.91 & 31.57 & 36.51 & 26.56 & 31.52 & 35.74 \\
\hline Total PUFAs & 31.87 & 44.55 & 44.16 & 49.37 & 38.04 & 43.17 & 46.57 \\
\hline
\end{tabular}

meal diets produced higher lipid compositions than the control group. The fillet lipid content of fish fed the 10 and $15 \%$ flaxseed diets exceeded $9 \%$. Moisture, ash, fiber, nitrogen-free extract, and energy contents were not significantly different $(P>0.05)$ among the experimental diets. The fillet protein contents $(33.59 \pm$ 
Table 2. Growth performance of Oreochromis niloticus fed different dietary inclusions of chia (C) and flaxseed (F) meal 45 days before harvesting (mean \pm standard deviation). 5C: $5 \%$ chia meal dietary inclusion, 10C: $10 \%$ chia meal dietary inclusion, 15C: 15\% chia meal dietary inclusion, 5F: 5\% flaxseed meal dietary inclusion, 10F: 10\% flaxseed meal dietary inclusion, 15F: $15 \%$ flaxseed meal dietary inclusion.

\begin{tabular}{lcccccc}
\hline & $\begin{array}{c}\text { Final weight } \\
(\mathrm{g})\end{array}$ & $\begin{array}{c}\text { Weight gain } \\
(\mathrm{g})\end{array}$ & $\begin{array}{c}\text { Specific } \\
\text { growth rate } \\
\left(\% \mathrm{~d}^{-1}\right)\end{array}$ & $\begin{array}{c}\text { Food } \\
\text { conversion } \\
\text { ratio (FCR) }\end{array}$ & $\begin{array}{c}\text { Viscerosomatic } \\
\text { index (VSI) }\end{array}$ & $\begin{array}{c}\text { Hepatosomatic } \\
\text { index (HSI) }\end{array}$ \\
\hline Control & $317.30 \pm 36.7$ & $139.80 \pm 37.2$ & $1.23 \pm 0.27$ & $1.57 \pm 0.57$ & $4.35 \pm 0.47$ & $1.82 \pm 0.09$ \\
5C & $353.10 \pm 36.4$ & $117.60 \pm 12.6$ & $0.90 \pm 0.10$ & $1.93 \pm 0.23$ & $6.09 \pm 0.57$ & $1.93 \pm 0.28$ \\
10C & $347.80 \pm 33.4$ & $131.90 \pm 27.8$ & $1.07 \pm 0.18$ & $1.73 \pm 0.39$ & $6.61 \pm 0.29$ & $2.29 \pm 0.16$ \\
15C & $379.50 \pm 40.3$ & $132.70 \pm 21.9$ & $0.97 \pm 0.18$ & $1.87 \pm 0.37$ & $6.78 \pm 1.38$ & $2.15 \pm 0.76$ \\
5F & $333.40 \pm 40.1$ & $109.20 \pm 23.2$ & $0.83 \pm 0.12$ & $2.13 \pm 0.58$ & $5.88 \pm 0.46$ & $2.24 \pm 0.28$ \\
10F & $341.80 \pm 34.9$ & $168.00 \pm 36.1$ & $1.35 \pm 0.15$ & $1.30 \pm 0.30$ & $6.92 \pm 0.69$ & $2.54 \pm 0.20$ \\
15F & $364.50 \pm 25.6$ & $131.80 \pm 8.7$ & $1.03 \pm 0.18$ & $1.67 \pm 0.12$ & $6.06 \pm 0.36$ & $2.27 \pm 0.17$ \\
\hline
\end{tabular}

$0.29 \%)$ were similar for all treatments $(P<0.05)$ except for the $10 \%$ flaxseed diet, which was lower only than that found in the control diet. The ALA and total n-3 PUFA contents in tilapia fillet differed significantly among treatments $(P<0.05$, Table 2$)$; diets containing $15 \%$ chia or flaxseed meal had the highest concentrations of ALA (4.80 and $4.75 \%$, respectively) and total n-3 PUFA contents (13.65 and $15.92 \%$, respectively). The inclusion of chia or flaxseed meal did not affect $(P>0.05)$ the saturated, monosaturated, and $n-6$ PUFA contents of the tilapia fillet.

Vertebrates require PUFAs for normal growth and development (Olsen et al. 1990). Previous research has shown that high levels of PUFAs in different tilapia species depress growth and feed efficiency (Huang et al. 1998, Ng et al. 2001). Ng et al. (2013) compared the effects of a partial replacement of FO with different vegetable oils as finishing diets for tilapia in growth and feed efficiency. Moreover, Al-Souti et al. (2012) reported similar SGR (1.84-1.97 \% d $\left.\mathrm{d}^{-1}\right)$ and FCR (1.561.70) when comparing partial substitutions of FO with different levels of corn oil in the diet of red hybrid tilapia (Oreochromis sp.). In the present study, levels of dietary lipids exceeded $10 \%$; nevertheless, growth and feed efficiency were within the appropriate range for this tilapia species at the age tested. Our results, obtained with different percentages of chia and flaxseed meals used as finishing diets, produced similar SGR and FCR to those previously reported. Survival and SGR after 45 days were normal and in general agreement with other reports for adult tilapia (Bahnasawy et al. 2003). Differences in the growth and feed efficiency values between the studies mentioned above may be partially explained by fish size, lipid source, and culture time.

Except for ALA, there were no significant differences among the experimental diets regarding the fatty acid profile of tilapia muscle. Levels of arachidonic acid (ARA) were similar in the control and experimental diets. ARA is the main product of linoleic acid desaturation (Karapanogiotidis et al. 2007) and represents the primary eicosanoid precursor to aid in resisting stress, among other roles. Lim et al. (2011) stated that the fatty acid composition in fish muscle could be modified by increasing dietary levels of PUFAs. The significantly increased ALA concentration in the tilapia fillets was clearly demonstrated after 45 days $(P<0.05)$ and was proportional to the percentage of seed meal included in the diet. Other researchers have reported that tilapia can elongate and desaturate ALA to EPA and DHA (Tocher et al. 2002, Oboh et al. 2017).

Moreover, EPA is a precursor of DHA and is used in basic metabolism (Albertazzi \& Coupland 2002), explaining when EPA concentrations remained low and without significant changes. A variety of metabolic factors affect the incorporation of fatty acids into tissues, such as desaturation, $\beta$-oxidation, lipogenic activity, and chain lengthening (Sargent et al. 2002), as well as exogenous (environment) and endogenous (fish age and size) factors. In this study, deposition of EPA in muscle was low for all diets, which could be explained by the supposition that EPA is selectively used as a substrate for $\beta$-oxidation in $O$. niloticus (Karapanogiotidis et al. 2007).

Our results indicate that chia and flaxseed meal may be used to partially replace some of the fish oil typically used in finishing diets as an additional feeding strategy for Nile tilapia (Karapanogiotidis et al. 2007) without compromising its growth performance. Moreover, using these dietary lipid sources (in the form of a meal instead of oil) represents a useful and potential dietary alternative to increase the nutritional value of tilapia fillet. Improving tilapia fillet quality through chia or 
Table 3. Proximate and fatty acid composition (\% dry basis) of Oreochromis niloticus fillet fed finishing diets (45 days before harvesting) enriched with different levels of chia $(\mathrm{C})$ and flaxseed $(\mathrm{F})$ meal (mean \pm standard deviation). 5C: 5\% chia meal dietary inclusion, 10C: $10 \%$ chia meal dietary inclusion, 15C: $15 \%$ chia meal dietary inclusion, 5F: 5\% flaxseed meal dietary inclusion, 10F: 10\% flaxseed meal dietary inclusion, 15F: 15\% flaxseed meal dietary inclusion. Different letters in columns show statistically significant differences $(P<0.05)$.

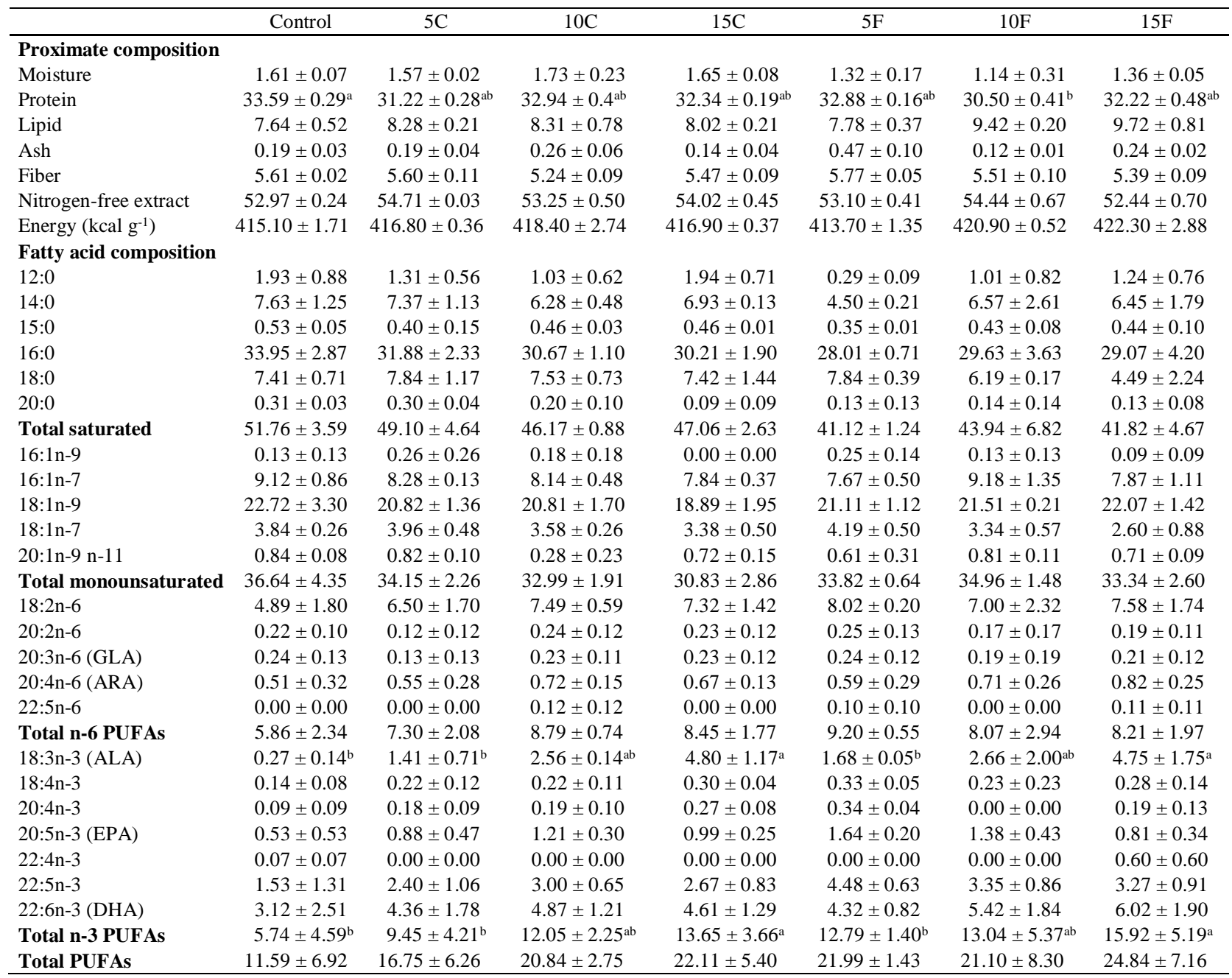

flaxseed meal inclusion will facilitate achieving worldwide recommendations on these fatty consumption acids that favor human health.

\section{ACKNOWLEDGMENTS}

Funding was provided by Instituto Politécnico Nacional (SIP-IPN 20100697; 20150267). M. Muñoz is a recipient of a doctoral fellowship from CONACYT (grant 337709). H.R.G., S.M.G., L.G.E.A. and M.G.U. are fellows of COFAA and EDI of the Instituto Politécnico Nacional.

\section{REFERENCES}

Ackman, R.G. 1980. Fish lipids, part 1. In: Connell, J.J. (Ed.). Advances in fish science and technology. Fishing News Books, Farnham.

Albertazzi, P. \& Coupland, K. 2002. Polyunsaturated fatty acids. Is there a role in postmenopausal osteoporosis prevention? Maturitas, 42: 3-22.

Al-Souti, A., Al-Sabahi, J., Soussi, B. \& Goddard, S. 2012. The effects of fish oil-enriched on growth, feed conversion and fatty acid content of red hybrid tilapia, Oreochromis sp. Food Chemistry, 133: 723-727. 
Association of Analytical Chemists (AOAC). 1990. Standard official methods of analysis of the Association of Analytical Chemists. AOAC, Washington, DC.

Bahnasawy, M.H., Abdel-Bak, T.E. \& Abd-Allah, G.A. 2003. Growth performance of Nile tilapia (Oreochromis niloticus) fingerlings raised in an earthen pond. Archives of Polish Fisheries, 11: 277-285.

Carbonera, F., Bonafe, E.G., Martin, C.A., Montanher, P.F., Ribeiro, R.P., Figueiredo, L.C., et al. 2014. Effect of dietary replacement of sunflower oil with perilla oil on the absolute fatty acid composition in Nile tilapia (GIFT). Food Chemistry, 1: 230-234.

Christie, W.W. 1982. The preparation of derivatives of lipids. In: Christie, W.W. (Ed.). Lipid analysis. Pergamon Press, New York.

Food and Agriculture Organization (FAO). 2016. The state of world fisheries and aquaculture 2016: contributing to food security and nutrition for all. FAO, Rome.

Fernandes-Montanher, P., Costa e Silva, B., GutendorferBonafé, E., Carbonera, F., Celestino dos Santos, H.M., De Lima-Figuereido I., et al. 2016. Effects of diet supplementation with chia (Salvia hispanica L.) oil and natural antioxidant extract on the omega-3 content and antioxidant capacity of Nile tilapia fillets. European Journal of Lipid Science and Technology, 118: 698-707.

Folch, J., Lees, M. \& Sloane-Stanley, G.H. 1957. A simple method for the isolation and purification of total lipid from animal tissues. Journal of Biological Chemistry, 226: 497-509.

Huang, C.H., Huang, M.C. \& Hou, P.C. 1998. Effect of dietary lipids on fatty acid composition and lipid peroxidation in sarcoplasmic reticulum of hybrid tilapia, Oreochromis niloticus x O. aureus. Comparative Biochemistry and Physiology - Part A: Molecular \& Integrative Physiology, 120: 331-336.

Justi, K.C., Hayashi, C., Visentainera, J.V., De Souza, N.E. \& Matsushita, M. 2003. The influence of feed supply time on the fatty acid profile of Nile tilapia (Oreochromis niloticus) fed on a diet enriched with n3 fatty acids. Food Chemistry, 80: 489-493.

Karapanogiotidis, I.T., Bell, M.V., Little, D.C. \& Yakupitiyage, A. 2007. Replacement of dietary fish oils by alpha-linolenic acid-rich oils lowers omega 3 content in tilapia flesh. Lipids, 42: 547-559.

Kromann, N. \& Green, A. 1980. Epidemiological studies in the Upernavik district, Greenland. Acta of the Medicine Scandinavica, 208: 401-406.

Lim, C., Yildirim-Aksoy, M. \& Klesius, P. 2011. Lipid and fatty acid requirements of tilapia. North American Journal of Aquaculture, 73: 188-193.
Ng, W.K. \& Hanim, R. 2007. Performance of genetically improved Nile tilapia compared with red hybrid tilapia fed diets containing two protein levels. Aquaculture Research, 38: 965-972.

Ng, W.K., Lim, P.K. \& Sidek, H. 2001. The influence of a dietary lipid source on growth, muscle fatty acid composition and erythrocyte osmotic fragility of hybrid tilapia. Fish Physiology and Biochemistry, 25: 301-310.

Ng, W.K., Chong, C.Y., Wang, Y. \& Romano, N. 2013. Effects of dietary fish and vegetable oils on the growth, tissue fatty acid composition, oxidative stability and vitamin E content of red hybrid tilapia and efficacy of using fish oil finishing diets. Aquaculture, 372-375: 97-110.

Oboh, A., Kabeya, N., Carmona-Antoñanzas, G., Castro, L.F.C., Dick, J.R., Tocher, D.R. \& Monroig, O. 2017. Two alternative pathways for docosahexaenoic acid (DHA, 22: 6n-3) biosynthesis are widespread among teleost fish. Scientific Reports, 7: 3889.

Olsen, R.E., Henderson, R.J. \& McAndrew, B.J. 1990. The conversion of linoleic acid and linolenic acid to longer-chain polyunsaturated fatty acids by tilapia (Oreochromis niloticus) in vivo. Fish Physiology and Biochemistry, 8: 261-270.

Petenuci, M.E., Schneider, V.V.A, Lopes, A.P., Gonçalves, R.M., Dos Santos, V.J., Matsushita, M. \& Visentainer, J.V. 2018. Effect of alpha-linolenic acid sources in diets for Nile tilapia on fatty acid composition of fish fillet using principal component analysis. Journal of Aquatic Food Product Technology, 27: 464-476.

Sargent, J.R., Tocher, D.R. \& Bell, J.G. 2002. The lipids. In: Halver, J.E. \& Hardy, R.W. (Eds.). Fish nutrition. Academic Press, New York.

Steffens, W. 1997. Effects of variation in essential fatty acids in fish feeds on nutritive value of freshwater fish for humans. Aquaculture, 151: 97-119.

Tonial, I.B., Stevanato, F.B., Matsushita, M., De Souza, N.E., Furuya, W.M. \& Visentainero, J.V. 2009. Optimization of flaxseed oil feeding time length in adult Nile tilapia (Oreochromis niloticus) as a function of muscle omega-3 fatty acids composition. Aquaculture Nutrition, 15: 564-568.

Tocher, D.R. \& Harvie, D.G. 1988. Fatty acid compositions of the major phosphoglycerides from fish neural tissues: (n-3) and (n-6) polyunsaturated fatty acids in rainbow trout (Salmo gairdneri L.) and cod (Gadus morhua) brains and retinas. Fish Physiology and Biochemistry, 5: 229-239.

Tocher, D.R., Agaba, M., Hastings, N., Bell, J.G., Dick, J.R. \& Teale, A.J. 2002. Nutritional regulation of hepatocryte fatty acid desaturation and polyunsaturated 
fatty acid composition in zebrafish (Danio rerio) and tilapia (Oreochromis niloticus). Fish Physiology and Biochemistry, 24: 309-320.

Valenzuela, A. \& Uauy, R. 1999. Consumption pattern of dietary fats in Chile: n-6 and n-3 fatty acid. Journal of Food Science Nutrition, 50: 97-119.

Van de Vis, H., Kestin, S., Robb, D., Oehlenschlager, J., Lambooij, B., Munkner, W., et al. 2003. Is humane slaughter of fish possible for industry? Aquaculture Research, 34: 211-220.

Visentainer, J.V., Carvalho, P.O., Ikegaki, M. \& Park, Y.K. 2000. Concetraçāo de ácido eicosapentaenóico (EPA) e ácido docosaheaenóico (DHA) em peixes marinhos da costa brasileira. Ciência e Tecnologia de Alimentos, 20: 90-93.

Received: October 8, 2020; Accepted: June 1, 2021
Visentainer, J.V., De Souza, N.E., Makoto, M., Hayashi, C. \& Franco, M.R.B. 2005. Influence of diets enriched with flaxseed oil on the a-linolenic, eicosapentaenoic and docosahexaenoic fatty acid in Nile tilapia (Oreochromis niloticus). Food Chemistry, 90: 557560.

Visentainer, J.V., Noffs, M.D., Carvalho, P.O., Almeida, V.V., Oliveira, C.C. \& Souza, N.E. 2007. Lipid content and fatty acid composition of 15 marine fish species from the southeast coast of Brazil. Journal of the American Oil Chemists' Society, 84: 543-547.

Weaver, K.L., Vester, P., Chilton, J.A., Wilson, M.D., Pandey, P. \& Chilton, F.H. 2008. The content of favorable and unfavorable polyunsaturated fatty acids found in commonly eaten fish. Journal of the American Dietetic Association, 108: 1178-1185. 